Fountain Journal of Natural and Applied Sciences: 2016; 5(2): 1 - 6
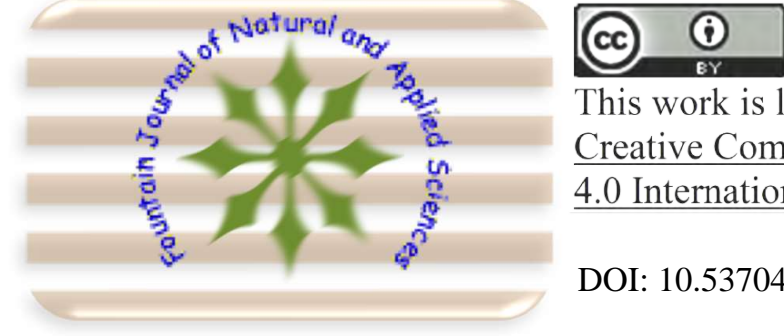

This work is licensed under

Creative Commons Attribution 4.0 International License.

DOI: 10.53704/fujnas.v5i2.90

A publication of College of Natural and Applied Sciences, Fountain University, Osogbo, Nigeria. Journal homepage: www. fountainjournals.com ISSN: 2354-337X (Online), 2350-1863 (Print)

\title{
Study of Surface Modification of Electrospun Polyethylene Oxide Composite Fibre
}

\author{
${ }^{1 \star}$ Alayande, S.O., ${ }^{2}$ Bolarinwa, H.S., ${ }^{3}$ Akinsipo, B.O., ${ }^{4}$ Ofudje, A., ${ }^{1}$ Fasasi, A.Y., \\ ${ }^{1}$ Ajao, J.A., ${ }^{1}$ Pelemo, D.A. and ${ }^{1}$ Osinkolu, G.A. \\ ${ }^{1}$ Centre for Energy Research and Development, Obafemi Awolowo University, Ile Ife, Nigeria. \\ ${ }^{2}$ Department of Physics, Electronics and Earth Sciences, Fountain University, Osogbo, Nigeria \\ ${ }^{3}$ Department of Chemistry, College of Science and Information Technology, Tai Solarin University of \\ Education, Ijagun, Ijebu-ode, Nigeria \\ ${ }^{4}$ Department of Chemical Sciences McPherson University, Ogun State, Nigeria
}

\begin{abstract}
Functionalization of polymers had gained attention because of advance applications as sensor, energy devices, membrane, etc. This present study is aimed at studying surface modification as a result of electrospinning functionalized polyethylene oxide (PEO) with zinc ion. Zinc chloride was added in various proportions to PEO solution then electrospun at various voltage. Fibres resulted into various shapes; belt, rod, mat and thread which differs from the primary PEO. The mechanism for the morphology modification was studied and the optimum conditions which retain the fibrous morphology were noted. This functionalized PEO can be used as energy device.
\end{abstract}

Keyword: Polyethylene oxide, Modification, Fibre, Composite, Functionalized

\section{Introduction}

Composite materials are referred to as wonder material due to low weight, corrosion resistance, high fatigue strength, modified structures and faster assembly (Josmin, et al., 2012). They are materials that consist of two or more interfaces which are different in term of chemical and physical properties. They have found applications in various areas: electronic, automobile, construction, medical, etc. (Josmin, et al.,2012) 2012). Many viable composites are found in nature; wood is a natural composite of cellulose fibre in a matrix of lignin, connective tissues in mammals is a polymer composites which comprises fibrous protein and collagen (Josmin, et al., 2012). Fibrous composites can be divided into natural/bio fibre and synthetic composite fibre. Synthetic composite fibres are obtained from non-natural materials which can be copolymers, metal-polymer, inorganic-organic fibre. Polymer based composite fibre can be obtained using techniques such as drawing, template synthesis, phase separation, self assembly and electrospinning (Buchko, Kozloff, \& Martin, 2001) (Fujihara, Lim , Ma, Ramakrishna, \& Teo, 2005) (Zheng-Ming, Zhang,

Corresponding author: Alayande, S. O

Email address: gbengaalayande@gmail.com 
Kotaki, \& Ramakrishnab, 2003). Electrospinning process is the only process that can be scaled up for mass production of continues fibre (Fujihara, Lim, Ma, Ramakrishna, \& Teo, 2005) (Zheng-Ming, Zhang, Kotaki, \& Ramakrishnab, 2003), it is simple and versatile method to generate ultrathin fibre. The name electrospinning was derived from electrostatic spinning, which involves the application of high voltage to a polymer solution in which charges are induced with resultant fibre production. Ultrathin fibre electrospun had been reported from over fifty polymers (Fujihara, Lim - Ma, Ramakrishna, \& Teo, 2005), co-polymers (Fujihara, Lim , Ma, Ramakrishna, \& Teo, 2005) (Zheng-Ming, Zhang, Kotaki, \& Ramakrishnab, 2003), polymer-inorganic, inorganic oxides and ceramic (Zheng-Ming, Zhang, Kotaki, \& Ramakrishnab, 2003) (Chronakis, 2005) with fibre diameter in the micro and nano dimension. Fibres greater than $1 \mu \mathrm{m}$ are micro-fibre while 1$1000 \mathrm{~nm}$ are referred to as nano fibre. Composite materials made from micro fibres had been reported to have superior structural properties such as high modulus, strength to weight ratio in comparison with parent composite (Fujihara, Lim , Ma, Ramakrishna, \& Teo, 2005). Nanofibre had advantages over microfibre based on higher surface area. Composite materials containing nanofibres are called nanocomposites.

Several composite fibre had been reported from electrospinning technique: (Kim \& Reneker, 1999) studied the reinforcing effect of electrospun nanofibres of polybezinidazole in an epoxy and rubber matrix, Bergshoef et. al. (Bergshoef \& Vancso, 1999) fabricated nanocomposite using Nylon-4, 6 nanofibre non woven membrane. Also composite ceramic hollow nanofibre through electrospinning had been fabricated.

PEO has been reported to be used as an anti-foaming agent in food (US Government Food and Drug Agency, 2011), insulator (Ueno, et al., 2008), potentiator (Harmening, 2005), lubricatant coating (Nalam, Clasohm, Mashaghi, \& Spencer, 2009), membrane, surfactants, packaging material (Rossi, 2006) (Geisbert, et al., 2010), laxatives (Palma Di, Cleveland, McGowan, \& Herrera, 2007)and drug delivery while Zinc chloride is used as flux for soldering (Harmening, 2005), catalyst (Cooper, 1955) (Shriner, Ashley,
\& Welch, 1955), fire proofing agent, textile processing, smoke grenades (Sample, 1997), finger print detection and disinfectant (Watts, 1869).

Considering the numerous potentials of composite electrospun fibre, this present study aims at investigating the morphological rearrangement which will occur when polyethylene oxide (PEO) is functionalized with zinc ion in electrospinning experiment, functionalized nanofibres are applicable for use as membrane, sensors, protective clothing, drug delivery, etc (Zheng-Ming, Zhang, Kotaki, \& Ramakrishnab, 2003)

\section{Methodology}

$10 \%$ of $300,000 \mathrm{~g} / \mathrm{mol}$ PEO solution was prepared in distill water while $40 \%, 45 \%$ and $50 \%$ of $\mathrm{PEO} / \mathrm{ZnCl}_{2}$ solutions were prepared in distill water in the ratio of 0.5:0.2, 0.5:0.3,0.5:0.4 and 1:1 respectively. The solutions were stirred for 12 hours then filled into the spinneret and spun between 10-30 kV. A schematic diagram of the electrospinning set up is shown in Fig. 1. The fibres were characterized using scanning electron microscope. Chemicals used were of analytical grade.

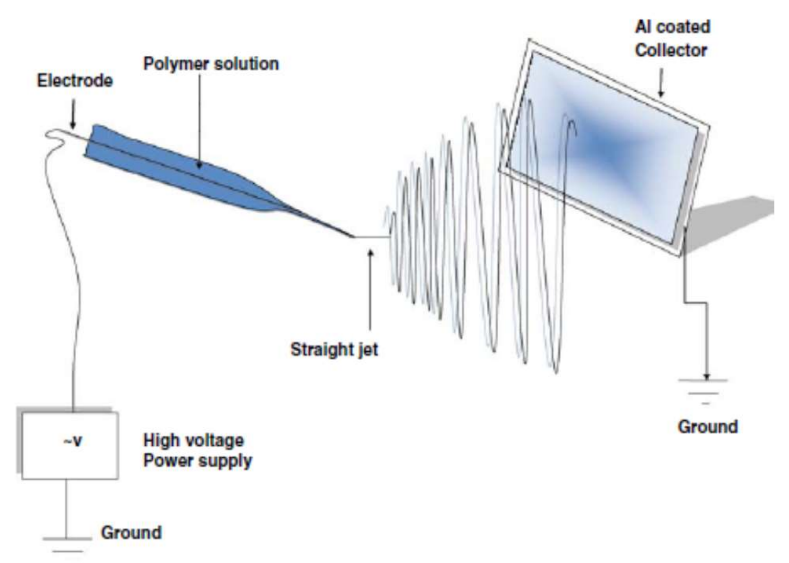

Fig. 1: Electrospinning set up

\section{Results and Discussions}

Figure 2 shows electrospun 25\% PEO solution, the fibre was bead free with $0.65 \mu \mathrm{m}$ functionalized PEO solution electrospun at 30,28 while figure 3 shows the micrographs of $40 \%$ and 
$24 \mathrm{kV}$. There was complete change in the fibre morphology in comparison with Figure 2. Spherical crown was observed in figure 3 (a) at $30 \mathrm{kV}$ but higher magnification (Figure $3(b)$ ) revealed that the crown was made up of regular shaped flakes with fibre growth at the root. The average length of the flakes was $7.07 \mu \mathrm{m}$. Furthermore, Figure 3 ( $c$ and $d$ ) shows a complete and incompletely formed spherical crown at 28kV. Figure $3(\mathrm{~d})$ reveals an irregular shaped flake which makes up figure 3(c). At a lower voltage
$24 \mathrm{kV}$ an array of incompletely formed flakes was observed (figure $3(f \& g)$ ). The incompletely formed spherical crown was observed to be made up of moist particles rather than fibre, with no fibre root. Figure $4(a-g)$ shows micrograph of electrospun of $45 \%$ functionalized PEO solution at different voltages. $A$ hollow tube with average diameter of $13.23 \mu \mathrm{m}$ was observed at $28 \mathrm{kV}$ (Figure $4(a-b)$ ) while fibre with rough surface with average size of $1.26 \mu \mathrm{m}$ was obtained at 26 kV (Figure 4(c-d)). At lower voltage non-hollow

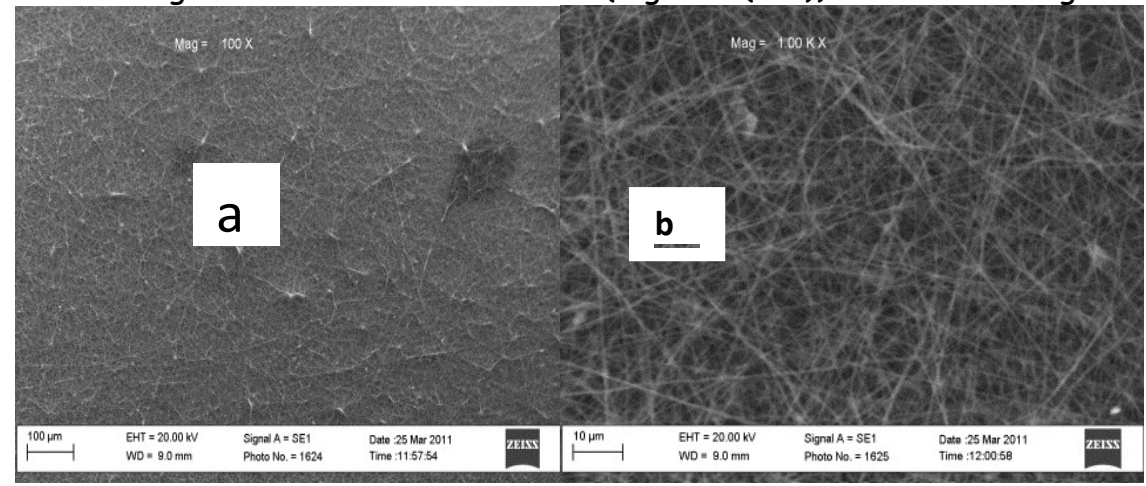

Figure 2: Scanning Electron Micrographs of PEO (a) at 1000x (b) at 100x

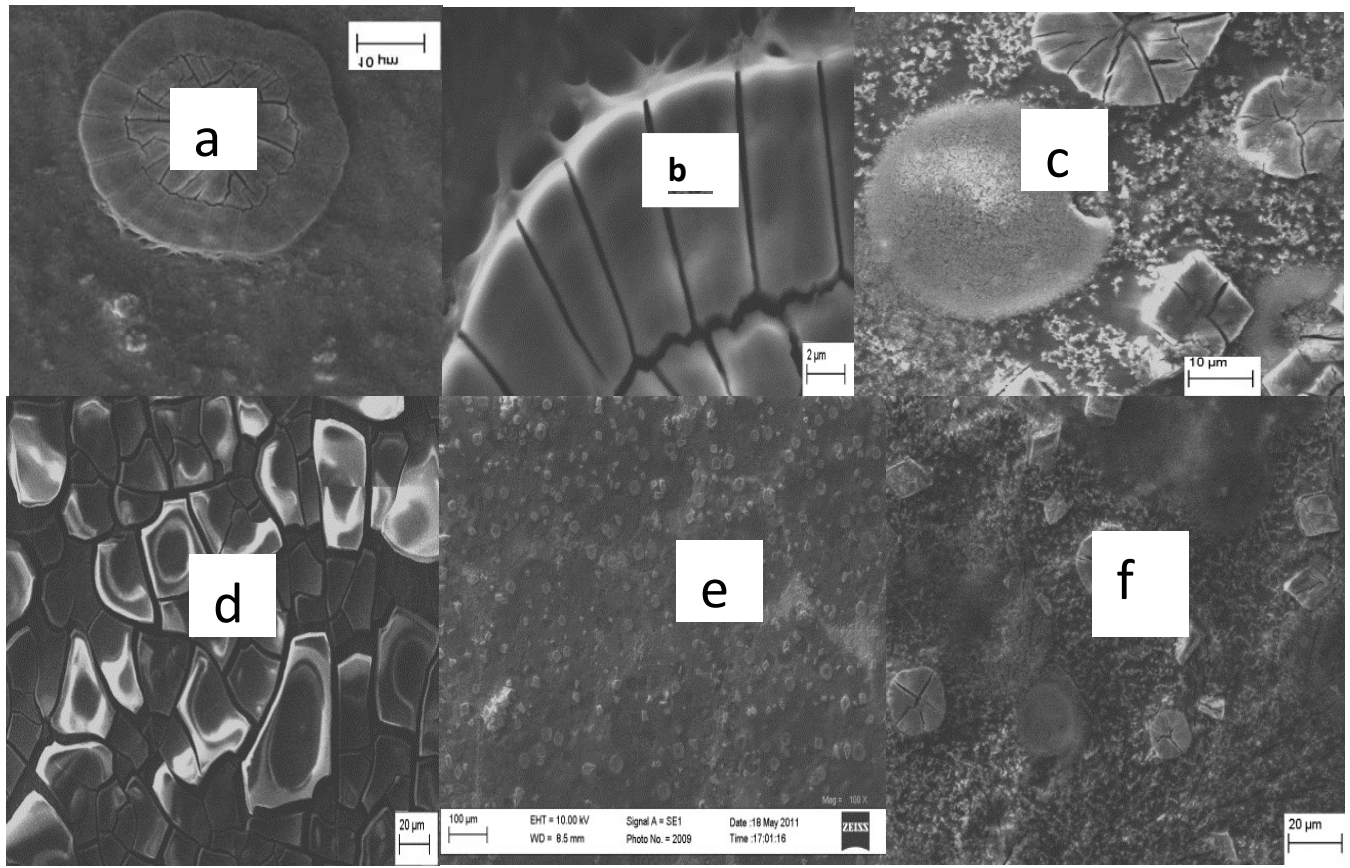

Figure 3: Scanning Electron Micrographs of Electrospun $40 \% \mathrm{PEO} / \mathrm{ZnCl}_{2}$ (a) $30 \mathrm{kV}$ at $1000 \times$ (b) $30 \mathrm{kV}$ at $1500 \mathrm{kV}$ (c) $28 \mathrm{kV}$ at $1740 x$ (d) $28 \mathrm{kV}$ at $1000 x$ (e) $24 \mathrm{kV}$ at $100 x(f) 24 \mathrm{kV}$ at 500x 


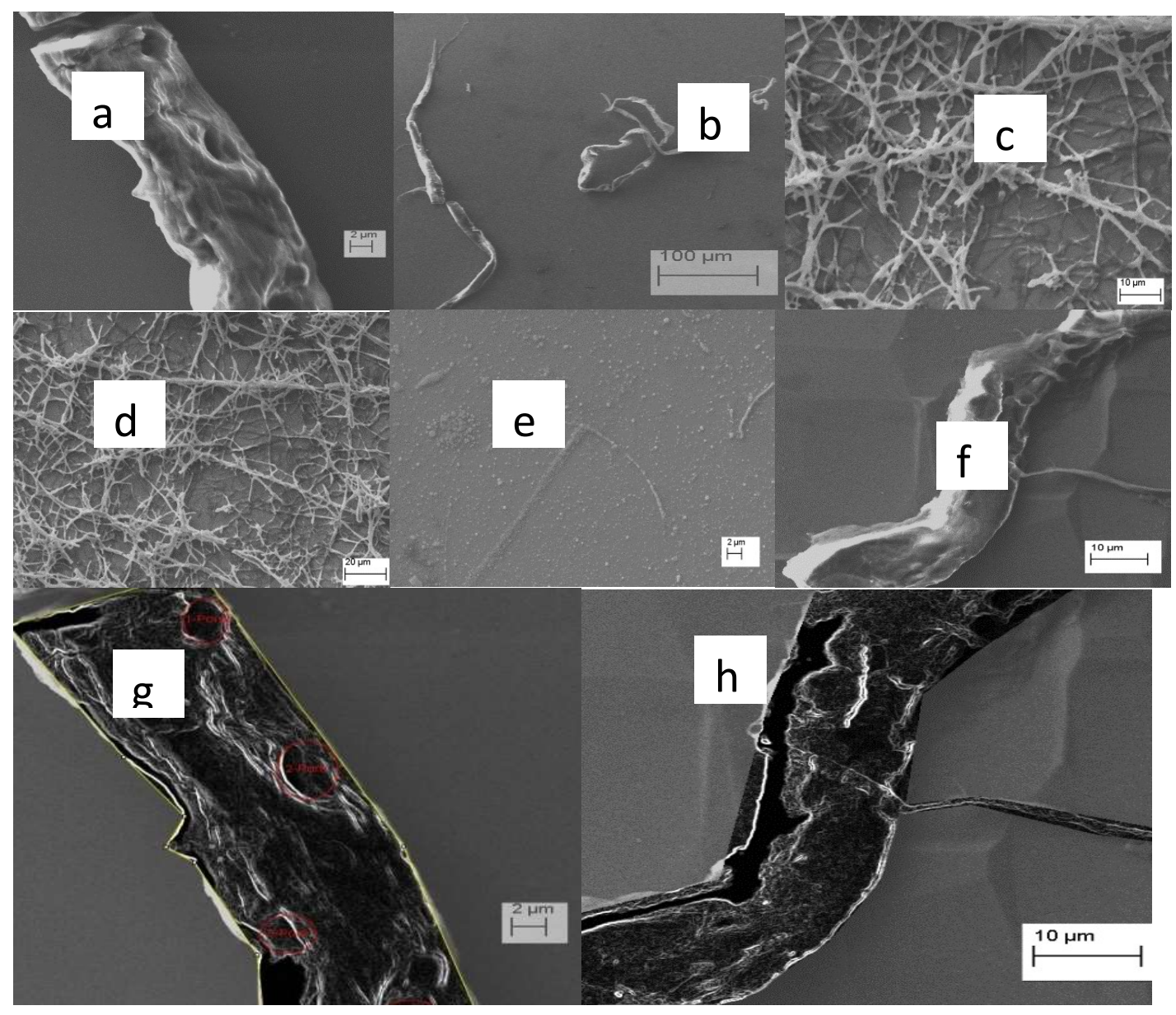

Figure 4: Scanning Electron Micrographs of Electrospun 45\% PEO/ZnCl 2 (a) $28 \mathrm{kV}$ at $2000 x$ (b) $28 \mathrm{kV}$ at $100 \times$ (c) $26 \mathrm{kV}$ at $1000 \times$ (d) $26 \mathrm{kV}$ at 500x (e) $24 \mathrm{kV}$ (f) $22 \mathrm{kV}$ (g) $28 \mathrm{kV}$ at 2000x modified (h) 22 $k V$ modified

tube was observed which has an average diameter of $13.60 \mu \mathrm{m}$. Further analysis of hollow and nonhollow tube formed showed that the tubes were made of fibre (Figure 4 ( $g$ and $h$ )). Figure $5(a-d)$ shows morphology of $50 \%$ solution fibre at $30 \mathrm{kV}$, $26 \mathrm{kV}$ and $24 \mathrm{kV}$. At $30 \mathrm{kV}$, fibre presented a beltlike morphology with an average width of $29.61 \mu \mathrm{m}$ (Figure 5(a-b)), while at 24 and $26 \mathrm{kV}$, a mat-like morphology was obtained as shown in Figure 5 ( $c$ and d). A notable experimental parameter which was responsible for change in surface morphology of this functionalized PEO solution is voltage. In electrospinning process, voltage plays a prominent role in the determination of resultant morphology (Zheng-Ming, Zhang, Kotaki, \& Ramakrishnab, 2003). At high voltage, essential charges in the solution together with the external electric field will be initiated when the surface tension of the solution is overcome be electrostatic force (Zheng-Ming, Zhang, Kotaki, \& Ramakrishnab, 2003). In the case of these functionalized PEO solutions with same viscosity, as voltage increases, the amount of charges remove will cause the jet to accelerate faster and volume of solution which will be drawn from the tip of the spinneret will simultaneously increase resulting in smaller and less stable Taylor cone (Buchko, Kozloff, \& Martin, 2001; Zheng-Ming, Zhang, Kotaki, \& Ramakrishnab, 2003; Fujihara, Lim, Ma, Ramakrishna, \& Teo, 2005;). Also, stretching and acceleration of the jet are factors which are dependent on voltage supplied as well as resultant electric field, stretching of the polymer solution will increase with voltage due to columbic forces 


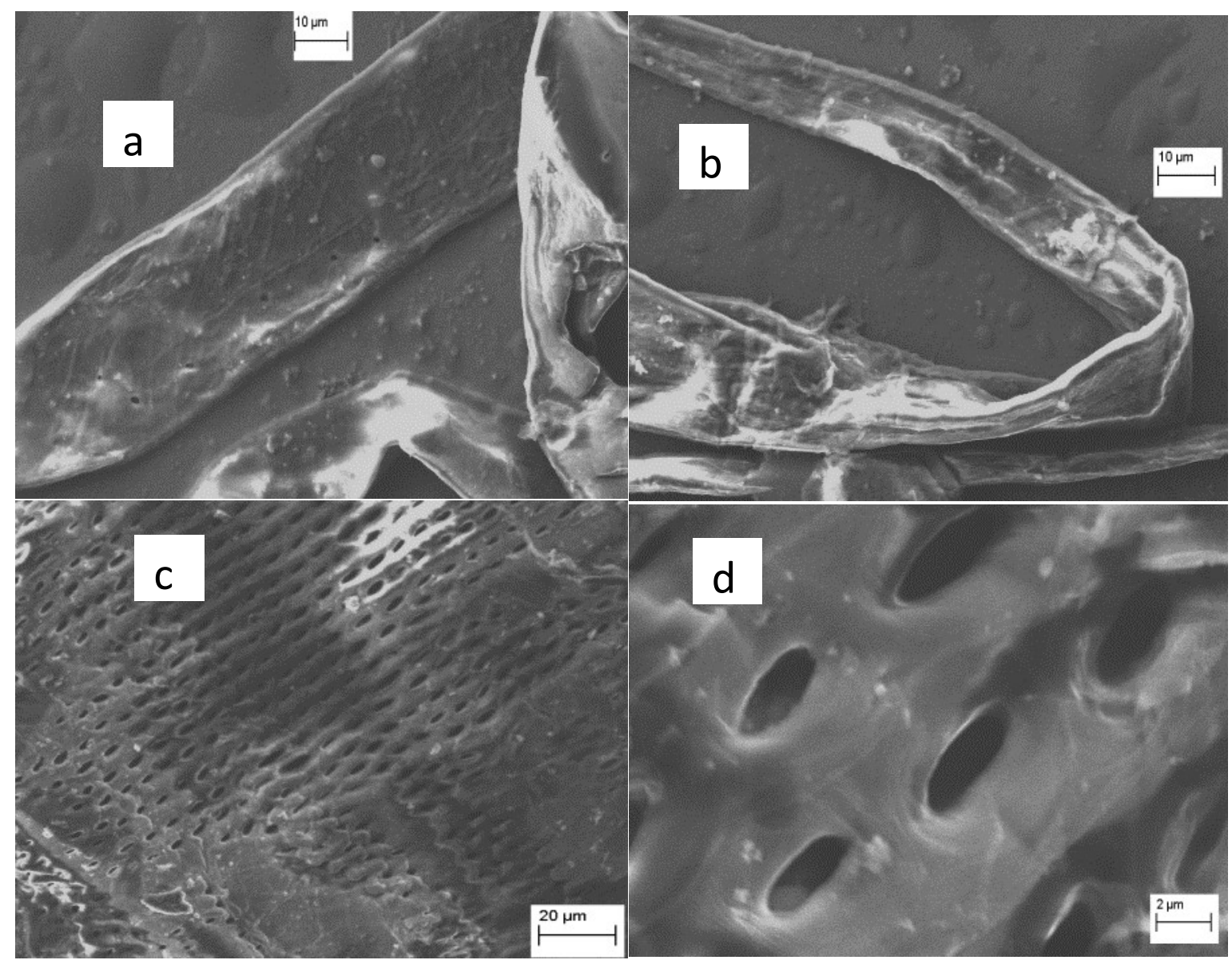

Figure 5: Scanning Electron Micrographs of Electrospun 50\% PEO/ZnCl (a) $30 \mathrm{kV}$ at $2000 \times$ (b) $30 \mathrm{kV}$ at $500 \times$ (c) $26 \mathrm{kV}$ (d) $24 \mathrm{kV}$

in the spinneret which increase with electric field. Hence higher voltage favours the evaporation of solvent yielding a dry fibre obtained in figure 3(a\&b), hollow fibre (figure $4(a, b \& g)$ ) and belt (figure 5(a\&b)).

Another factor under the polymer concentration which is crucial in modification of the composite morphology is viscosity. The difference in surface morphology can also be attributed to difference in viscosity across the concentration while similarity was observed within solutions of same viscosity. Increase in the solution concentration will increase the viscosity while decrease in solution concentration will decrease viscosity. Larrondo et al., (Larrondo \& Manley, 1981) showed that viscosity was crucial when they electrospun fibres from melt. Viscosity affects fibre morphology because at very low viscosity polymer particles are formed, electrospraying occurred rather than electrospinning. This factor is responsible for difference in morphologies.

\section{Conclusion}

Due to different applications (membrane, drug delivery, sensor, energy, etc) of electrospun functionalized polymer fibre, it is important that reaction condition must be optimized in which the surface modification of the composite must remain fibrous. In view of this, the optimum condition for fibrous morphology was $45 \% \mathrm{PEO} / \mathrm{Zn2}^{+}$at $26 \mathrm{kV}$. Other morphologies obtain will be useful as membrane (porous fibres), biomedical scaffold and sensors.

\section{References}

Bergshoef , M. M., \& Vancso, G. J. (1999). Transparent nanocomposites with ultrathin, electrospun Nylon-4,6 fiber reinforcement. Advance Material, 11(16), 1362-1365. 
Buchko, C. J., Kozloff, K. M., \& Martin, D. C. ( 2001). Surface characterization of porous, biocompatible protein polymer thin films. Biomaterials, 1289-1300.

Chronakis, I. S. (2005). Novel nanocomposite and nanoceramics based on polymer nanofibres using electrospinning process-A review. Journal of Materials Processing Technology, 167, 283-293.

Cooper, S. R. (1955). Resacetophenone. Organic Synthensis, 3, 761.

Fujihara, K., Lim , T., Ma, Z., Ramakrishna, S., \& Teo, W. (2005). An Introduction to Electrospinning and Nanofibres. Singapore: World Scientific Publishing Co. Pte. Ltd.

Geisbert, T. W., Lee, A. C., Robbins, M., Geisbert, J. B., Honko, A. N., Sood, V., ... De Jong, S. (2010, 05 29). Postexposure protection of non-human primates against a lethal Ebola virus challenge with RNA interference: a proof-of-concept study. The Lancet, 375(9729), 1896 - 1905. doi:10.1016/S0140-6736(10)60357-1

Harmening, D. M. (2005). Modern Blood Banking \& Transfusion Practices. F. A. Davis Company.

Holleman, A. F., \& Wiberg, E. (2001). Inorganic Chemistry. San Diego: Academic Press.

Josmin, J. P., Malhotra, S. K., Thomas, S., Joseph, K., Goda, K., \& Sreekala, M. S. (2012). " Advances in Polymer Composites: Macroand Microcomposites - State of the Art, New Challenges, and Opportunities". $K G a A$ : Wiley- $\mathrm{VCH}$ Verlag $\mathrm{GmbH}$ \& Co. $K G a A$.

Kim, J. S., \& Reneker, D. H. (1999). Mechanical properties of composites using ultrafine electrospun fibers. Polymer Composites, 20(1), $124-131$.
Larrondo, L., \& Manley, R. (1981). Electrostatic fibre spinning from polymer melts. $J$ Polymer SCii: Polymer Physics, 19, 933 940.

Nalam, P. C., Clasohm, J. N., Mashaghi, A., \& Spencer, N. D. (2009). Macrotribological Studies of Poly(L-lysine)-graft-Poly(ethylene glycol) in Aqueous Glycerol Mixtures. Tribology Letters, 37(3), 541. doi:10.1007/s11249-009-9549-9

Palma Di, J. A., Cleveland, M. v., McGowan, J., \& Herrera, J. L. (2007). A Randomized, Multicenter Comparison of Polyethylene Glycol Laxative and Tegaserod in Treatment of Patients With Chronic Constipation. The American Journal of Gastroenterology, 102(9), $1964-1971$.

Rossi, J. J. (2006). RNAi therapeutics: SNALPing siRNAs in vivo. Gene Therapy, 13(7), 583-584. doi:10.1038/sj.gt.3302661

Sample, B. E. (1997). Methods for Field Studies of Effects of Military Smokes, Obscurants, and Riot-control Agents on Threatened and Endangered Species. DIANE Publishing.

Shriner, R. L., Ashley, W. C., \& Welch, E. (1955). 2Phenylindole. Organic Synthensis, 3, 723.

Ueno, K., Nakamura, S., Shimotani, H., Ohtomo, A., Kimura, N., Nojima, T., .. . Iwasa, Y. (2008). Electric-field-induced superconductivity in an insulator. Nature Materials, 7(11), 855 - 858. doi:10.1038/nmat2298

US Government - Food and Drug Agency. (2011, 10 21). Listing of Food Additive Status Part II.

Watts, H. (1869). A Dictionary of Chemistry and the Allied Branches of Other Sciences. Longmans, Green.

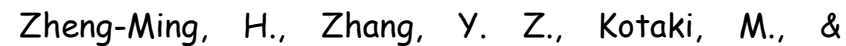
Ramakrishnab, S. (2003). A review on polymer nanofibers by electrospinning and their applications in nanocomposites. Composites Science and Technology, 63, 2223-2253 